\title{
Development of Power Operated Coir Removal Machine
}

\author{
Yashas S, Krishnamurthy J \\ Undergraduate Student, \\ Department of Mechanical Engineering, Visvesvaraya Technical University, \\ East West Institute of Technology, Anjana Nagar, \\ Bengaluru, Karnataka 560-091
}

\begin{abstract}
In general, Coconuts are de-husked manually using either a machete or a spike. These methods require skilled labor and are tiring to use. Attempts made so far in the development of de-husking tools have been only partially successful and not effective in replacing manual methods. Considering the drawbacks of manual de-husking methods, and existing automated de-husker, power operated coconut de-husking machine was developed.

This power operated coconut de-husking machine operates on 3-phase, $\mathbf{2}$ hp electric motor. It mainly consists of parts like frame, electric motor, speed reduction unit and de-husking unit. Single person is required for operating the de-husker.

During the tests, average time required for de-husking a coconut was found to be 25 second, and the machine can dehusk 120-150 coconuts per hour. Therefore by using this machine time and labor cost is saved to great extent.
\end{abstract}

Key words: Coconuts, De-husking, Electric motor.

\section{I.INTRODUCTION}

The machine proposed in this work essentially performs two procedures. They are sbellicando and crown is taking off. Stripping is the way toward evacuating the stringy part (shell) from the nut. It has been an issue since days of yore. Albeit numerous sorts of coconut stripping hardware have been created most sterilization tasks are done physically, which demonstrates that there are no better machines created than handle coconuts. Coconut skin is the most central issue as far as work pursuit and profitability improvement. The following are a portion of the machines that are practically speaking.

The instrument in Figure 1.1 is the most normally utilized for shelled coconuts and is additionally exceptionally tamed. It comprises of a sharp edge where the coconut is set by applying power. At that point the collapsing edge opens with the assistance of the switch. This thus cuts and opens the coconut shell.

This is done in various introductions and the rest of the shell is expelled until the coconut is totally stripped. It is a manual procedure and requires a lot of exertion with respect to the specialist .It is additionally perilous in light of the fact that an accomplished laborer can get injured simultaneously.

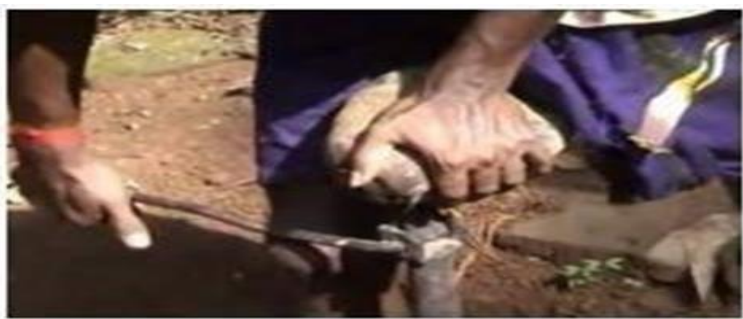

Figure 1.1: Manual De-husking Tool

The machine appeared in Figure 1.2 is known as a peeler and is one of the cutting edge and most inventive strategies produced for the stripping of coconuts. The development lies in the way that the machine expels the coconut shell as effectively as the external skin of the banana natural product is stripped off. It is a decent arrangement as far as debarking quality and finishes the descaling procedure with the most astounding conceivable productivity. Despite the fact that it doesn't require any power to be practiced by the laborer, it is as yet not gainful on the grounds that it requires an administrator to work the machine consistently. It utilizes joins initiated by pneumatic or switch systems to evacuate the coconut shell. It is additionally a tedious procedure. Another inconvenience is that the strip after shedding isn't as simple to drive as in different strategies for handling coconut fiber.

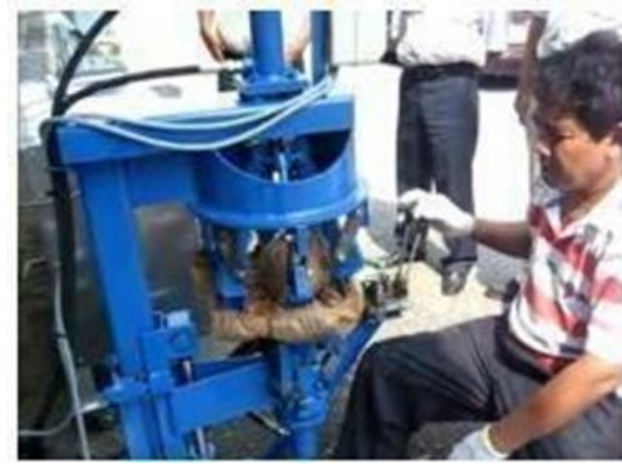

Figure 1.2: Coconut Husk Peeling Machine

The technique in Figure 1.3 is by a long shot the best strategy accessible for shell evacuation and is presently utilized in large scale manufacturing. It has two level rollers with sharp edges. This is like work. Nonetheless, coconuts must be held set up by a certain clipping power. The coconut is joined to the pivoting rollers by hand or by 
methods for a switch. The anticipated bleeding edges make the shell evacuation process. This likewise requires a consistent workforce. It quickens the procedure of disposal of the shell, in spite of the fact that the last efficiency as far as numbers depends to a great extent on the speed and limit of the laborer.

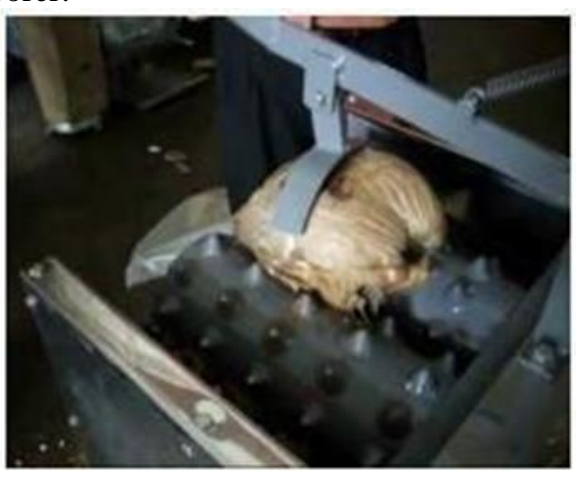

Figure 1.3:De-husking Machine

The coconut crown is a part of the coconut, that is processed in the machine. The crown is the fibrous portion that protrudes. It is seen by covering the eyes of the coconut. It is difficult to manually remove the crown from the nut. The crown is extracted for the production and cooking of the oil after the coconut has been cut two halves.

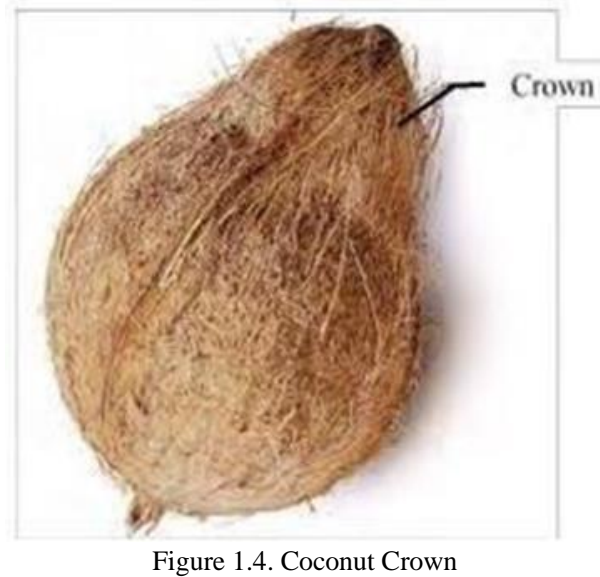

Coconut (Cocosnucifera) is the one most and important perennials in the world. The coconut fruit is composed of an external exocarp, a layer of thick fibrous fiber said to be shell, below there is endocarp or hard protective shell.

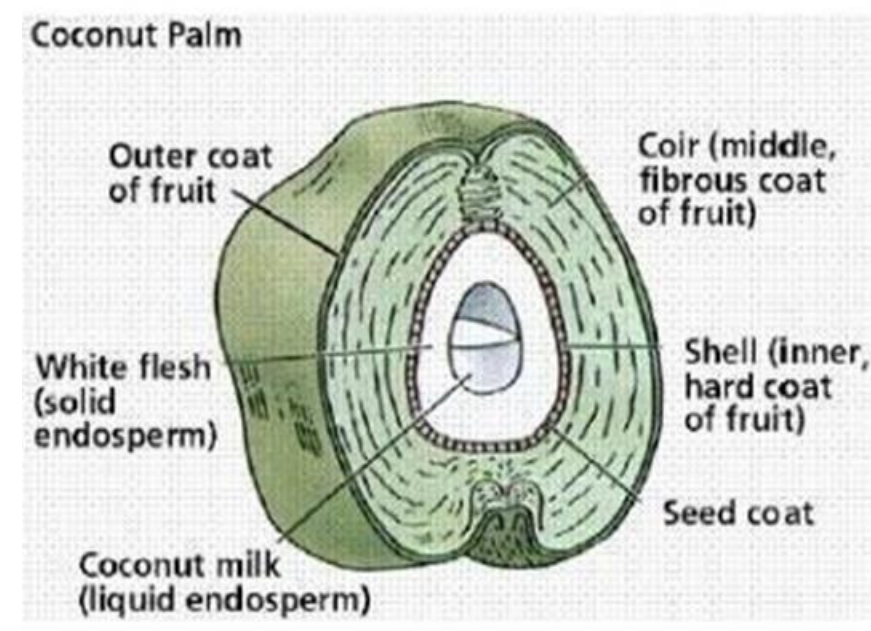

Figure 1.5: Parts of Coconut

The coconut palm is generally developed in the tropics. India is the world's third biggest maker of coconuts on the planet after the Philippines and Indonesia. Different makers are Thailand, Malaysia, Papua New Guinea and the Pacific islands. With coconut estates spreading over more than one million hectares, India delivers about 5.5 billion walnuts for each year. Copra created in the nation is about 0.35 million tons and India represents about half of the world exchange coconut fiber. Coconut estates are moved principally in the beach front and delta districts of southern India. In India, the gather is mostly created by little negligible ranchers who are around 5 million. The normal size of the homestead is just 0.25 hectares. With the declining of the issues of agrarian work and the abatement of water assets, an ever increasing number of sections of land of ranches are going from the ark to the coconut, since the last is simpler to become and progressively beneficial. Coconut generation assumes an essential job in the Indian national economy. As indicated by information distributed in December 2009 by the United Nations Food and Agriculture Organization, India is the third biggest maker of coconuts, with a creation of $10,894,000$ tons in 2009. Traditional agrarian coconut zones are Kerala (45.22\%), Tamilnadu (26.56\%), Karnataka (10.85\%), Andhra Pradesh (8.93\%) and Goa, Orissa, West Bengal, Pondicherry, Maharashtra and Laccadive and Andaman Islands and Nicobar.

Practically all coconut parts are helpful. Unripe natural product meat can transform into coconut frozen yogurt, while a ready coconut organic product can be eaten crisp or used to make ground coconut and nourishing cows. Coconut milk is an invigorating and nutritious beverage, while its oil is utilized for cooking and margarine. Coconut oil is additionally essential in cleanser generation. The lodging is utilized for fuel purposes, lodging gasifier as an elective wellspring of warm vitality. The shell produces filaments utilized in the assembling of coconut as coconut fiber woven coconut mats made out of coconut material belts, coconut plates, asbestos coconut marrow and coconut. Coir is a flexible common fiber removed from mesocarp tissue, or coconut shell organic product. For the most part the fiber is brilliant in shading when cleaned in 
the wake of expelling it from the coconut shell. The coconut is the sinewy shell of the coconut shell. Being solid and normally impervious to ocean water, the coconut fiber ensures the organic product enough to endure months glides on sea flows to be drawn up on a sandy shoreline where it can grow and develop in a tree on the off chance that you have enough crisp water, since the various supplements he needs were made with the seed.

The Coconut De-husker is a manual instrument. Comprises of three arrangements of edges, each comprising of 3 sharp edges. The upper unit has 2 sets of sharp edges and the lower half has a lot of edges. The upper sharp edge set will Despite the fact that the coconut has massive financial significance for both modern and provincial occupants, the division of its shell from the (stripped) nut comprises the main task, the most troublesome and risky of its handling. The utilization of a blade, which is the customary well known technique for woofing the coconut, speaks to a risk and a threat to the lives of the general population included, since in the yelping procedure, some cut their hands and impact when the cleaver It by and large ricochets when it hits the shell. The utilization of metal spikes was grown later to beat these negative qualities of natural product stripping, yet this consequent improvement concentrated just on removing coconut meat, in spite of the fact that mishaps, time and vitality utilization were decreased. The look for a gadget that permits the successful recuperation of different results of this natural product, for example, milk, skins and strands, has proceeded because of the significance of these coconut items in present day mechanical applications. Be that as it may, little scale country ranchers are the fundamental wellspring of coconut organic product for the country and the financial plan of this class of ranchers can't fulfill the colossal need for interests in both the electric generator and the costly mechanized de-huller gear of coconut which are for the most part of remote birthplace. Besides, the issue of the shortage of oil determined energizes, for example, petroleum and diesel in this nation since 1993, hampers the working of this electrical hardware. Consequently, most coconut ranchers in Nigeria still utilize the crude strategy for debarking blade cutting regardless of the unfavorable attributes of this procedure. Along these lines, it bodes well from a financial perspective if a physically worked machine that can strip the organic product without breaking the nut and twist the length of the removed fiber is created from standard and privately sourced materials to guarantee availability for the rancher. Little scale coconuts from this country and other creating nations. Countries in both procurement and support. Hence, the point of this investigation is to build up a coconut yelping machine equipped for stripping the organic product without breaking the nuts and contorting the length of the fiber removed for little country ranchers.

\section{II.LITRATURE SURVEY}

The manual coconut defroster is broadly utilized there to empty the coconut. An instrument of this sort comprises of two sheets, one is fixed to the vertical section and the other is portable. The mobile sharp edge is connected to the handle. At the point when constrain is connected to the handle, the jaw pivots, which removes. Amid descaling, the coconut is skewered on the sharp edges in the shut position, so the handle is raised to strip.

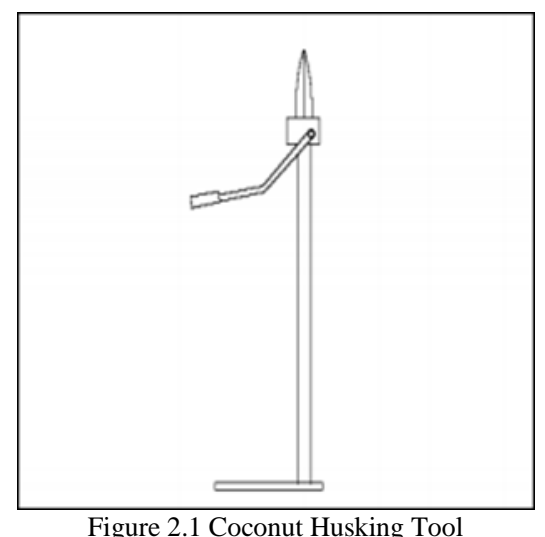

The Coconut De-husker is a manual instrument. Comprises of three arrangements of edges, each comprising of 3 sharp edges. The upper unit has 2 sets of sharp edges and the lower half has a lot of edges. The upper sharp edge set will initially infiltrate the shell, and after that the upper cutting edge set will segregate from the shell. This coconut deicer is made out of three arrangements of three jaws. When utilizing these jaws, the coconut drops.

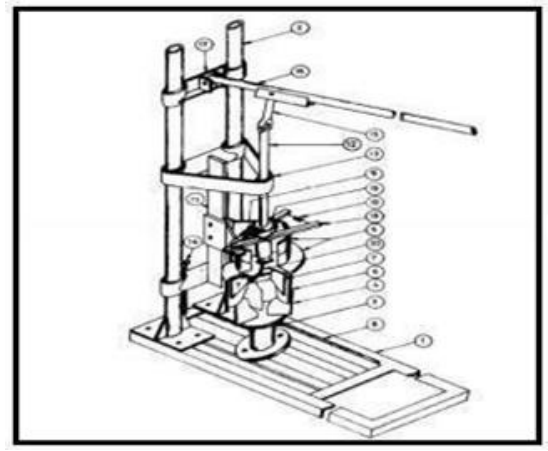

Figure 2.2 Hand Operated Coconut De-husking Machine

Youthful coconut is profoundly nutritious and is a standout amongst the most prominent sent out organic product assortments in Thailand. The natural product basically incorporates green calfskin, fiber extricate, meat wrap and squeeze. The development and improvement of youthful coconut organic product firmly impact the nature of the organic product. The juice and tissue of the unripe organic product are, in any case, unforgiving and an excess of delicate (coagulated), while those of the ready natural product are, individually, sweet and hard. The two stages are not supported by shoppers. The ready natural product is described by an agreeably sweet and marginally sharp squeeze and by a respectably delicate meat, which shoppers. There are a few changes in the physical attributes, in the mechanical quality, in the sonic and physiological properties that change with the development of the youthful coconut leafy foods identified by able organic product cultivators. This experience is close to home and isn't accessible to people in general. Youthful 
coconut sold in crisp markets are generally cut from the external shell with the goal that the coconut looks appealing and can be effectively opened.

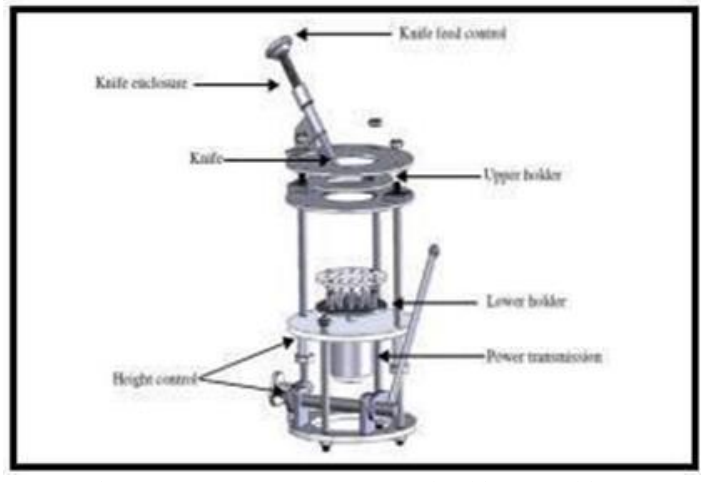

Figure 2.3 Young Coconut De-husking Machine

C. P. Waters et. Al, they built up an exceptionally basic idea to strip a coconut, utilizing a couple of tweezers with pointed tips. His work alludes to enhancements in coconut shell expulsion apparatuses. The created instrument has a couple of winding tweezers, which are provided with the handle and the tips are pointed. The tips are embedded into the shell with manual power. Subsequent to squeezing the handle with the goal that the tip embedded into the fiber endeavors to move away by expelling the fiber from the top. It is profoundly productive and practical, however all things being equal, there is a ton of manual power included and can make damage the specialist.

Edward Hill et. Al, they built up a straightforward however successful apparatus for stripping coconuts. The shell of coconuts is a difficult, moderate and rather unsafe undertaking. There is by all accounts no settled recipe for dealing with this task, yet it is generally finished with a blade or a cleaver. These can be hazardous, particularly when it is a coconut since it is undesirable. Besides, it set aside a long effort to finish the work, with the goal that it was anything but a gainful activity. This work gives a moderately straightforward device to cutting coconuts and one that is sheltered and can be effectively come to rapidly and without the requirement for past preparing. The device incorporates wedge-formed sharp edges that are constrained into the shell and afterward one of the cutting edges moves from the other to remove some portion of the stringy shell. This is rehashed until the whole shell is constrained from the seed. The whole task can be performed rapidly and effectively.

\section{III.MACHINE DESIGN}

The fundamental parts of the proposed coconut debarking machine are appeared in Figure 3.1 in Figure 3.5 and comprise of a machine outline, a drive component, a maintenance system and a roller type vane instrument.

The edge is the primary help structure on which different parts of this machine are mounted. The casing is a welded structure, worked with an edge iron of $50 \times 50 \times 5 \mathrm{~mm}$ with measurements of $933 \mathrm{~mm}$ long, $515 \mathrm{~mm}$ in width and 845.1 $\mathrm{mm}$ in stature.
The transmission instrument incorporates an engine, worm gear reducers with a belt drive framework and a pivoting shaft with a chain drive framework. To work the parts, a 2-hp enlistment engine with a speed of $1500 \mathrm{rpm}$ is utilized. The machine likewise utilizes a gearbox with a proportion of 70: 1 and associated with a hub, which is a long pivoting barrel that transmits vitality starting with one spot then onto the next. For the maintenance component, the help squares work by lessening the vibrations or motions caused amid revolution of the pole in longer lengths because of substantial burdens. In this way, to lessen the vibration of the machine, two help squares were utilized between the reducer and the rollers, while two others are situated at the correct end of the roller shaft. The instrument of the roller type can be clarified when two rollers, each with an extended setup, are masterminded isolating the pieces, considerably parallel to one another as for the base and in an effectively available design. Every roller is shaped by the welding of thirty-two metal teeth $(2$ x $20 \times 5 \mathrm{~mm}$ ) in a mellow steel tube $115 \mathrm{~mm}$ in distance across, mounted on a roller shaft.

Each pole of the roller is made of a delicate steel bar 40 $\mathrm{mm}$ in distance across, with a length of $890 \mathrm{~mm}$ for the principle shaft and a length of $644.87 \mathrm{~mm}$ for the parallel, upheld on the two finishes by heading at circle with a toothed wheel mounted on the left end. The cleaner is built by cutting the U-molded indents on an edge of a $2 \mathrm{~mm}$ thick gentle steel plate. The cleaners were fixed in the casing over the rollers. The machine for destroying the created coconut is anything but difficult to utilize and requires just a single administrator. At the point when the switch is turned on, the needle rollers pivot in inverse ways towards the inside, which causes the catch and breaking of the shell of the coconut natural product set between the rollers. The framework has been intended for a proficient debarking process in which the nuts will be disconnected with no breakage and, in this way, ensure a sufficient release of the stripped nuts.

\subsection{MACHINE FRAME}

The casing is the principle bolster structure on which different parts of this machine are mounted. The casing is a welded structure made of $50 \times 50 \times 5 \mathrm{~mm}$ precise gentle steel with measurements of $933 \mathrm{~mm}$ long, $515 \mathrm{~mm}$ in width and $845.1 \mathrm{~mm}$ in tallness. The steel is unbendingly fixed to the edge, with the goal that the vibration and weight are equally circulated to the hidden help outline. The geometric structure of the primary edge is intended to give great shape and stunningly better soundness to the whole structure. 


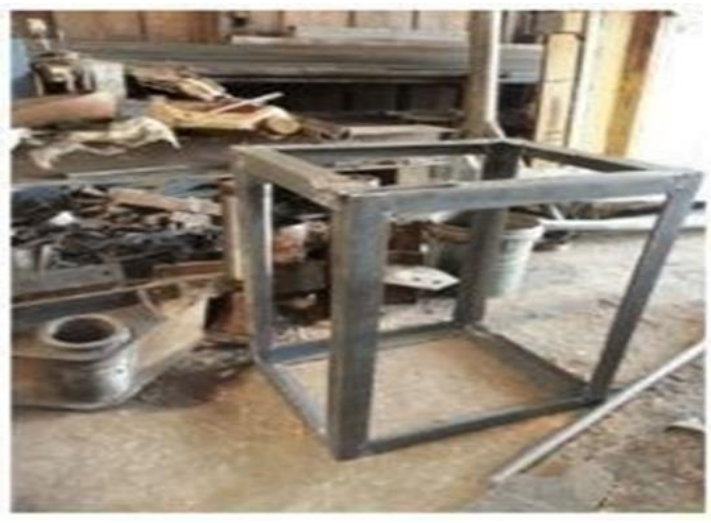

Figure 3.1 Main Frame

\subsection{DRIVE MECHANISM}

The component assumes an imperative job since the total task is precisely arranged. The general drive component is appeared in the figure:

- Motor

- Worm decrease gear box and belt drive framework

- Rotating shaft and chain drive framework.

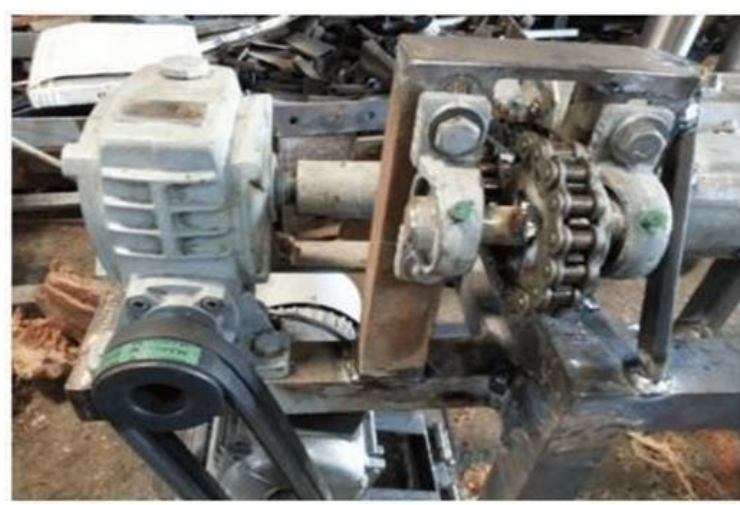

Figure 3.2 Main Drive Mechanism Components

\subsection{MOTOR}

A three-stage acceptance engine is utilized to drive the instrument. This motor is commonly utilized in different kinds of modern units. The engine goes about as a driving wheel associated by means of a belt framework legitimately to the gearbox that goes about as the driving wheel. The speed of pivot of the engine yield shaft is 1500 $\mathrm{rpm}$. The engine yield shaft is legitimately associated with the gearbox through a belt framework that totally decreases transmission misfortunes. The motor crankcase is unbendingly fixed to the machine outline. Care was taken with the goal that the crankshaft and the gearbox input shaft were participated in a parallel line to limit vibration and exploit motor power.

\subsection{REDUCTION GEARBOX}

Helical riggings are broadly used to transmit the intensity of rapid proportions. The gearbox utilized in this machine has a speed proportion of 35: 1 . This diminishes the speed from $1500 \mathrm{rpm}$ to $42 \mathrm{rpm}$. The instrument utilized in the gearbox is the worm screw system. The gearbox is coupled to the motor by a pulley associated with a V-belt. The yield of the gearbox is coupled to a long shaft that distends from the focal point of one of the rollers for coupling to the locking component. It comprises of the worm and the worm wheel. The worm is, basically, a barrel that has the wires similarly as a winding hinge. The worm is normally made of gentle steel, while the apparatus or wheel is made of cast iron or bronze for light employments.

\subsection{ROTATING SHAFT (MAIN SHAFT)}

A hub is a long turning chamber that transmits vitality starting with one spot then onto the next. Power is conveyed to the pole by digressive powers and the subsequent torque toward one side of the pole is associated with the yield of the reducer, while the opposite end is associated with the primary roller and also goes about as a help for the bearing framework.

\subsection{HOLDING INSTRUMENT}

The bearing squares are utilized to diminish vibrations or motions amid the turn of a long shaft with overwhelming burdens. In this way, to moderate the vibrations of the machine, two help squares are utilized between the reducer and the roller cutting edge, while two others are situated at the correct end of the roller shaft. Bearing squares are otherwise called upstanding squares. Its development is straightforward, so a direction is covered up inside a metal square and the metal square is inflexibly fixed in the machine outline. The help square is painstakingly focused with the goal that the pole hub and the help square are parallel to one another to diminish vibrations and motions amid task.

\subsection{ROLLER SORT CUTTING EDGE COMPONENT}

The roller instrument is to such an extent that two rollers, every one of which has a prolonged setup, are orchestrated and divided separated, considerably parallel to one another concerning the base and in an effectively open position. An inciting implies is additionally furnished to help the base and with direct coupling to the rollers. The interconnection of the rollers with the inciting implies is to such an extent that the rollers are obliged to turn toward a path inverse to one another and in a favored encapsulation which will be depicted in more prominent detail later, at generally unique paces. Together, the rollers characterize two uncovered outside surfaces, which can be considered as the upper pieces of the roller. In this introduction, the rollers pivot toward a path towards the center with the goal that a coconut, put inside it, will be constrained into the space between the rollers. 


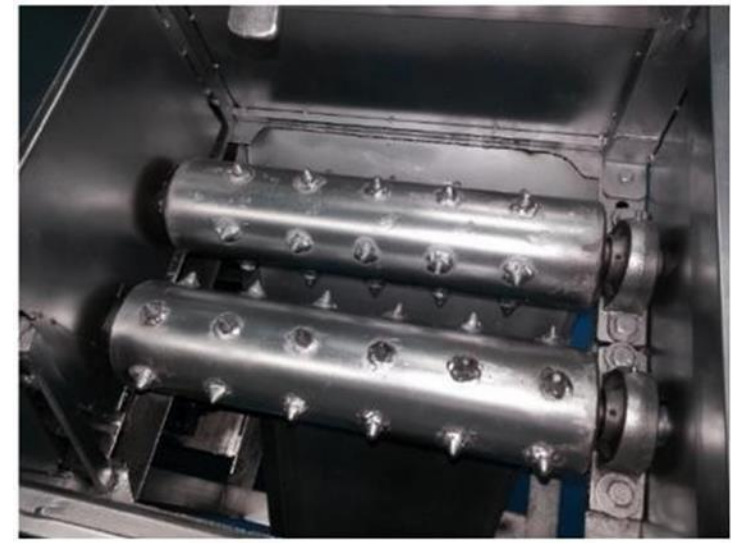

Figure 3.3 Roller Sort Cutting Edge Components

\subsection{PEELING SPIKES}

The pins that are associated with the pivoting shafts assume a key job in the stripping coconut. It acts like the device to the machine. The presence of methods for infiltration, framed on every edge formed like a Multi roller gives a viable stripping coconut shell. The pins are cone shaped and are divided considerably parallel separation from one another, with the goal that the arrangement of pins position to encourage infiltration, grasp and coconut tear. Nonetheless, the sharp focuses exchange with obtuse tips. Get the sharp-point coconut shell that enters her after the coconut enters the machine, while the unpolished tips tear shells. As it were, if the coconut is presented to a more extensive surface comprising of sharp focuses; it will expand the inclination to break the nut because of higher infiltration powers. Subsequently, this game plan is reasonable for evacuating fronts of ideal coconut proficiency.

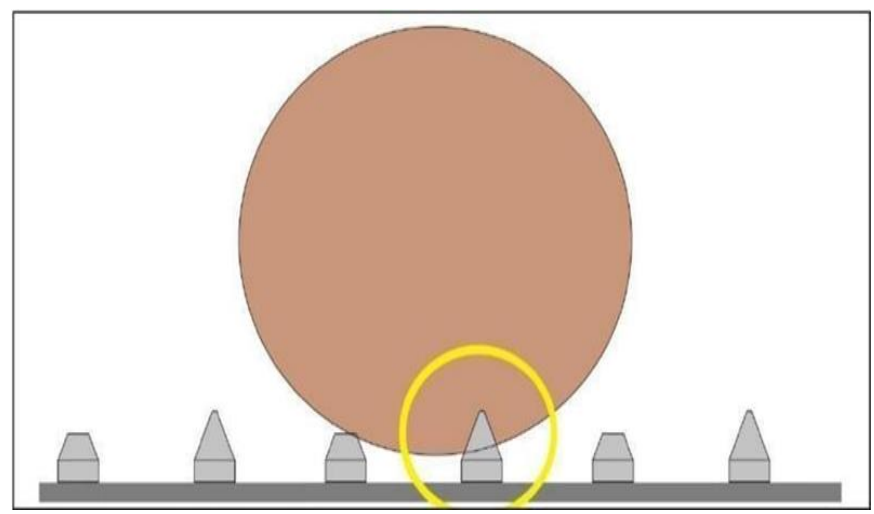

Figure 3.4 Action of the Spike on a Coconut

The slower pivots of the sharp edges, once infiltrated, make a tearing activity against the shell. Unmistakably the rollers must stay clean for a productive and compelling trade off with the coconut.

\section{IV.MATERIALS AND METHODOLOGY}

\subsection{MACHINE DESCRIPTION}

The fundamental segments of the coconut stripping machine created in Figure 4.1 are the edge, the debarking unit, the vehicle unit, the hindrance/cleaner plates, the handle and the bearing lodging.

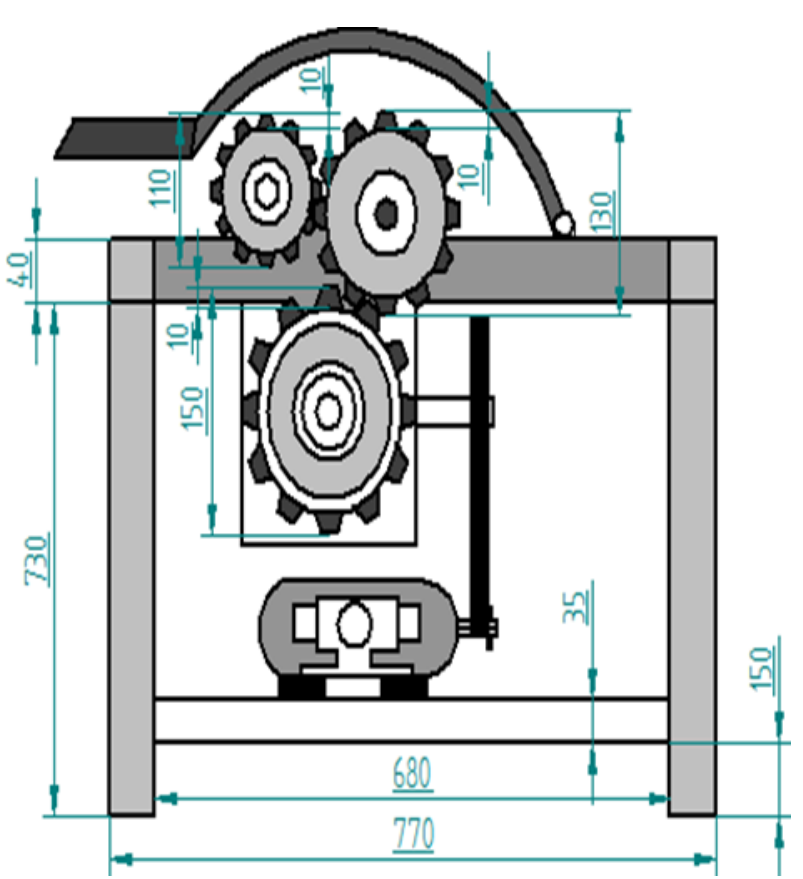

Figure 4.1 Diagram of The Developed Coconut De-husking Machine

The edge is the primary help structure on which different parts of this machine are mounted. The casing is a welded structure, worked with an edge iron of $50 \times 50 \times 5$ $\mathrm{mm}$ with measurements of $933 \mathrm{~mm}$ long, $515 \mathrm{~mm}$ in width and $845.1 \mathrm{~mm}$ in stature. The transmission instrument incorporates an engine, worm gear reducers with a belt drive framework and a pivoting shaft with a chain drive framework. To work the parts, a 2-hp enlistment engine with a speed of $1500 \mathrm{rpm}$ is utilized. The machine likewise utilizes a gearbox with a proportion of 70: 1 and associated with a hub, which is a long pivoting barrel that transmits vitality starting with one spot then onto the next. For the maintenance component, the help squares work by lessening the vibrations or motions caused amid revolution of the pole in longer lengths because of substantial burdens. In this way, to lessen the vibration of the machine, two help squares were utilized between the reducer and the rollers, while two others are situated at the correct end of the roller shaft. The instrument of the roller type can be clarified when two rollers, each with an extended setup, are masterminded isolating the pieces, considerably parallel to one another as for the base and in an effectively available design. Every roller is shaped by the welding of thirty-two metal teeth $(2 \times 20 \times 5 \mathrm{~mm})$ in a mellow steel tube $115 \mathrm{~mm}$ in distance across, mounted on a roller shaft.

Each pole of the roller is made of a delicate steel bar 40 $\mathrm{mm}$ in distance across, with a length of $890 \mathrm{~mm}$ for the principle shaft and a length of $644.87 \mathrm{~mm}$ for the parallel, upheld on the two finishes by heading at circle with a toothed wheel mounted on the left end. The cleaner is built by cutting the U-molded indents on an edge of a $2 \mathrm{~mm}$ thick gentle steel plate. The cleaners were fixed in the casing over the rollers. The machine for destroying the created coconut is anything but difficult to utilize and requires just a single administrator. At the point when the switch is turned on, the needle rollers pivot in inverse ways 
towards the inside, which causes the catch and breaking of the shell of the coconut natural product set between the rollers. The framework has been intended for a proficient debarking process in which the nuts will be disconnected with no breakage and, in this way; ensure a sufficient release of the stripped nuts,

1. The electric motor as a source of energy.

2. Gear train power transmitter.

3. Cylindrical rollers.

4. Threaded conical teeth.

5. Rotating plates.

6. Vertical turntable support.

7. Shaft and bearing assembly.

8. Change.

9. Mechanism for adjusting the intermediate distance of the cylinder.

10. Support panel.
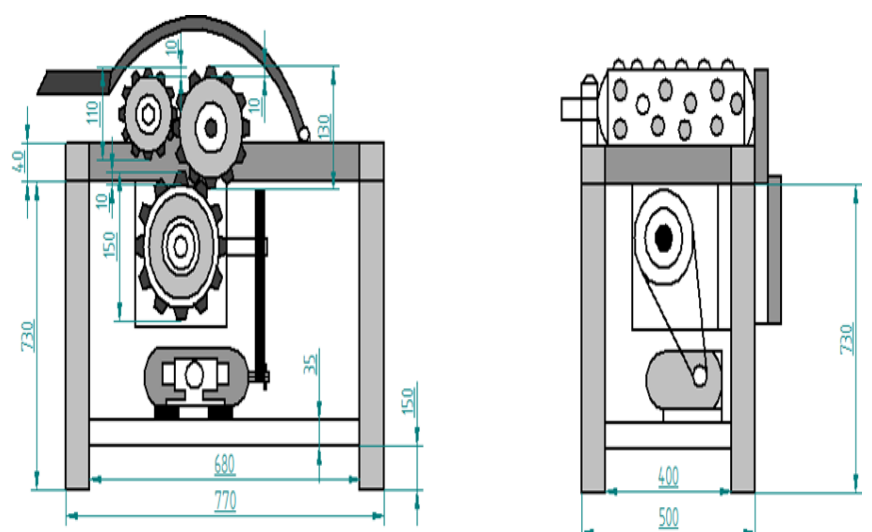

Figure 4.2 Cad Model of Coconut De-husking Machine

These elements mentioned above will be placed on the support frame. To transmit the engine power to the cylindrical rollers, it is necessary to incorporate a gear and pulley transmission system. The defrosting unit consists of cylindrical rollers joined with screws (cut pins) on the surface. The coconut is placed in the middle distance between the rolling cylinders. The rollers rotate in such a way that the coconut fiber of the shell tears. With an adequate network of fiber types, effective play with less time is achieved.

\begin{tabular}{|c|c|c|c|}
\hline Sr. no. & Description & Material & Composition \\
\hline 1. & $\begin{array}{l}\text { Cylindrical } \\
\text { Roller }\end{array}$ & EN24 & $\begin{array}{l}\text { Carbon- } 0.36 \% \\
\text { Silicon- } 0.20 \% \\
\text { Manganese- } 0.45 \% \\
\text { Sulphur- } 0.040 \%\end{array}$ \\
\hline 2. & Roller Shafts & $\begin{array}{l}\text { Stainless } \\
\text { Steel }\end{array}$ & $\begin{array}{l}\text { Carbon- } 0.15 \% \\
\text { Silicon- } 0.50 \% \\
\text { Manganese- } 1.00 \% \\
\text { Sulphur- } 0.03 \%\end{array}$ \\
\hline 3. & $\begin{array}{l}\text { Bearing } \\
\text { Supports }\end{array}$ & EN24 & $\begin{array}{l}\text { Carbon- } 0.36 \% \\
\text { Silicon- } 0.20 \% \\
\text { Manganese- } 0.45 \% \\
\text { Sulphur- } 0.040 \%\end{array}$ \\
\hline 4. & Frame & MS & $\begin{array}{l}\text { Carbon- } 0.29 \% \\
\text { Manganese- } 0.80 \%\end{array}$ \\
\hline
\end{tabular}

The shape and size of the coconut are considered during the design of the machine. From the studies conducted on the green and dry coconuts harvested in the middle lands of the two districts of Ernakulum and Kottayam of Kerala, in India, the physical properties of the coconut are the following

The average size of the coconut is as follows

1. Form: Ovoid

2. Dimensions: $300 \mathrm{~mm}$ long x $200 \mathrm{~mm}$ wide.

3. Fiber thickness: from 20 to $40 \mathrm{~mm}$

4. Weight: $1 \mathrm{~kg}$.

5. During descaling, the coconut shell is removed in 3 parts, each in width: from 40 to $80 \mathrm{~mm}$

Design of Various Element of Coconut De-husker shall be carried out as follows;

\subsubsection{DESIGN OF CUTTING SPIKES:}

The adhesion between the fibers in the shell is greater than that between the shell and the shell; therefore, the separation occurs in the shell interface. The fiber thickness is between 20 and $40 \mathrm{~mm}$. The size of tines should be selected in order to obtain an effective penetration with the coconut The screws can be joined to cylindrical rollers by welding or fixing devices. The advantage of using fasteners is that damaged wheels can be easily replaced.

\subsubsection{DESIGN OF CYLINDRICAL ROLLERS}

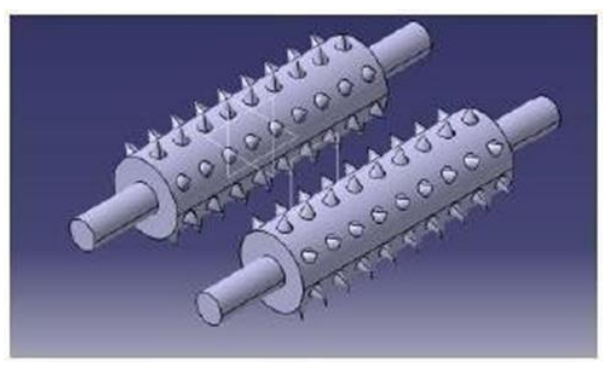

Figure 4.3 Cad Model of Cylindrical Rollers 
The dimensions of the cylinders are designed in such a way as to obtain an effective texture with coconut shell. Assumptions used,

1. Coconut contacts with cylinder with an average contact angle of 30 degrees

2. $1 / 6$ of the width of the coconut must be inserted into the space between the cylinders. (About $30 \mathrm{~mm}$ )

\subsubsection{HORIZONTAL AND CIRCULAR PITCH OF TINES}

Both the horizontal and the circular passage must be designed. The horizontal pitch is the distance between the axes along the axis or the length of the cylinder. The circular pitch is the distance between the wheels on the periphery of the cylindrical roller. To select the horizontal pitch, it is necessary to consider the average length of the coconut. It is located at $300 \mathrm{~mm}$. The tines are mounted in the cylinder in such a way that an optimal number of tines must be in contact with the coconut. This will help reduce the load on each unit and increase the efficiency of the deicing operation. To select the circular passage, the average width of the coconut is $200 \mathrm{~mm}$. You need to select the right number of tines for good mesh and effective clearance.

\subsection{POWER TRANSMISSION AND SPEED REDUCTION UNIT}

The power of the electric motor is transmitted to the rotating cylinders through pulleys and gears. The power must have less speed and high torque on the rotating cylinders and this is achieved by using a reduction in the gearbox speed. The gears and pulleys will be arranged in such a way that the desired performance is obtained by using gears and pulleys that are easy to find, to keep production costs low.

\section{V.FORCE ANALYSIS AND SPECIFICATION}

\subsection{FORCE ANALYSIS}

- 3 Phase Induction Motor With 1440rpm

- $\quad$ Tearing Force Required = 20kgf

- Power Required In Tearing:

$$
\begin{aligned}
& =(2 \Pi \mathrm{FN} / 60) * \text { no of rotation of coconut } \\
& {[(20 * 9.81)(2 * 3.14 * 0.15)(45 / 60)] * 4} \\
& =330 \mathrm{w}
\end{aligned}
$$

- Power Required For Driving The Coconut:

$$
\begin{aligned}
& =[(20 * 9.81)(3 / 60)] \\
& =10 \mathrm{w}
\end{aligned}
$$

- $\quad$ Total Power Required $=330+10=340 \mathrm{w}$

- Torque:

$$
=2 \Pi \mathrm{INT} / 60
$$$$
(340 * 60) /(2 * 3.14 * 1440)
$$

$$
=2.254 \mathrm{~N}-\mathrm{M}
$$

\subsection{DESIGN SPECIFICATION}

2hp motor.
Motor: 3 phase induction motor with 1440rpm

Shaft (hollow):

Length of the shaft $=400 \mathrm{~mm}$. number of shaft $=2$ numbers.
Diameter of the shaft $=90 \mathrm{~mm}$.

Gear type - spur gear:

Number of teeth on the driver gear $=42$

No of teeth on the driven gear $=24$

Diameter of the driver gear $=150 \mathrm{~mm}$

Diameter of the driven gear $=90 \mathrm{~mm}$

\section{- Gearbox specification:}

Speed ratio is $35: 1$

Speed reduction: $1500 \mathrm{rpm}$ to $42 \mathrm{rpm}$.

Diameter of output shaft $=25 \mathrm{~mm}$

\section{Bearing specification:}

Bearing series $=6200$ series

Bearing number $=6202$

Diameter of the bearing $=20 \mathrm{~mm}$

Spike specification:

Total length of the spike $=18 \mathrm{~mm}$

Sharpened length of the spike at end of a rod $=5 \mathrm{~mm}$

Angle of the sharpened edge $=135$ degree

\section{- Design of belt:}

$\mathrm{d} 1=60 \mathrm{~mm}$,

$\mathrm{d} 2=150 \mathrm{~mm}$

Center distance $=\mathrm{x}=0.78 \mathrm{~m}$

Length of belt $=1.905 \mathrm{~m}$

\section{VI.EXPERIMENTS AND DATA COLLECTION}

The elements of the develop coconut are critical with respect to the structure of the machine. A few homesteads and locales have been visited to comprehend the size range associated with the develop coconut. A few coconuts from the Andaman and Nicobar islands are exceptionally vast contrasted with the territories that develop with coconuts in India, for example, Tamil Nadu and Kerala. The machine has been intended to defeat a wide scope of coconut sizes, with equivalent significance for efficiency. Various places in Tamil Nadu and Kerala were transcendently considered to achieve an end on the span of coconuts. The measurements were estimated utilizing an outside calibrator. Most coconuts appear to have such measurements that the components of the $\mathrm{Y}$ and $\mathrm{Z}$ headings are practically indistinguishable. Be that as it may, the basic and stressing measurement of this machine show $\mathrm{X}$ measurement.

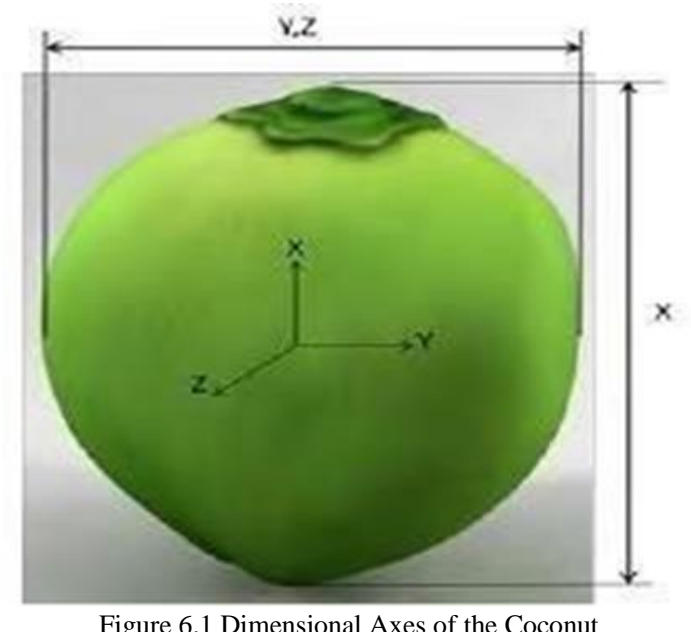

Figure 6.1 Dimensional Axes of the Coconut 
The dimensions of coconuts harvested from multiple points have been combined and few dimensions are presented in ascending order in the following table. The dimensions in the first row represent the smallest coconut and the dimensions in the last row represent the maximum size of the coconut.

\begin{tabular}{llll} 
No. & X-axis $(\mathrm{mm})$ & Y-axis $(\mathrm{mm})$ & Z-axis $(\mathrm{mm})$ \\
\hline 1 & 121 & 113 & 109 \\
2 & 157 & 146 & 142 \\
3 & 182 & 161 & 165 \\
4 & 246 & 218 & 214 \\
5 & 276 & 230 & 227 \\
6 & 287 & 269 & 263
\end{tabular}

Based on the above data, the stroke length of the pneumatic cylinders involved in the removal unit and in the crown extraction unit was derived.

\begin{tabular}{llll}
\hline No. & X-axis(mm) & Y-axis(mm) & Z-axis(mm) \\
\hline 1 & 97 & 86 & 86 \\
2 & 114 & 98 & 96 \\
3 & 125 & 115 & 109 \\
4 & 147 & 129 & 125 \\
5 & 162 & 135 & 134
\end{tabular}

Table 6.2 Dimensions of the Peeled Coconut

In addition to the above, some data is needed on the loads acting on the coconut to peel it. The shell is removed from the machine through the cutting force exerted by the fixed tooth Therefore, in relation to this, the amount of load required to break down the coconuts was determined. Both dried and mature coconuts of different sizes are experimentally determined on the UNIVERSAL STANDARD TESTING MACHINE (UTM). The mechanical properties of coconut fibre are studied by the works for this purpose.

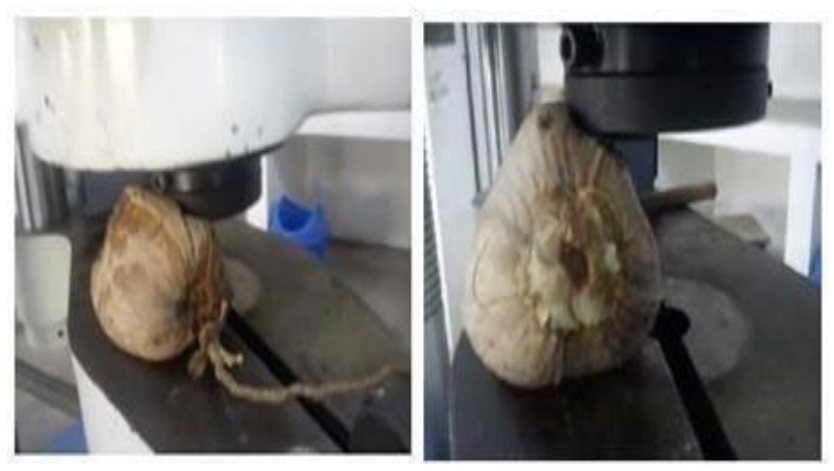

Figure 6.2 Sample coconut in UTM

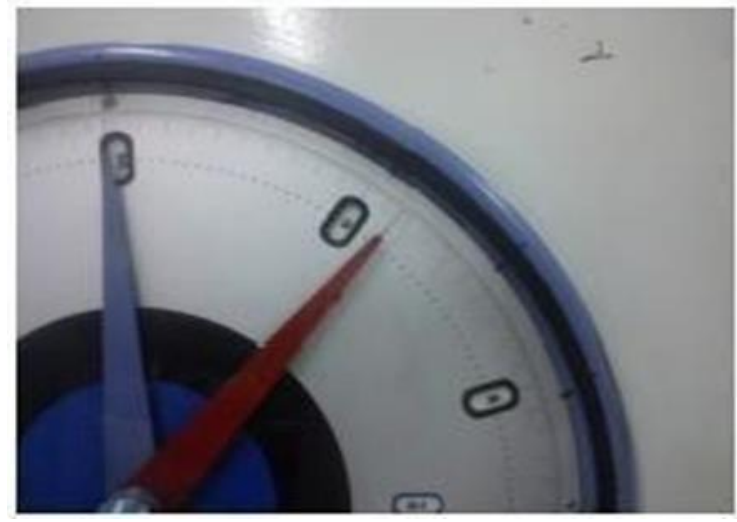

Figure 6.3 Upload to UTM

Below is the cutting load needed to peel a ripe coconut of different sizes.

\begin{tabular}{|c|c|c|c|}
\hline No. & Dimension in X-xxis (mm) & Shear Load (kN) & Mature Coconut \\
\hline 1 & 128 & 0.32 & \\
\hline 2 & 145 & 0.35 & \\
\hline 3 & 178 & 0.39 & \\
\hline 4 & 212 & 0.45 & \\
\hline 5 & 248 & 0.52 & \\
\hline \multicolumn{4}{|c|}{ Table 6.3 Cutting Load Needed To Shell Ripe Coconuts } \\
\hline No. & Dimension in X-2xis (mm) & Shear Load (kN) & Dry Coconut \\
\hline 1 & 133 & 0.24 & \\
\hline 2 & 154 & 0.26 & \\
\hline 3 & 174 & 0.29 & \\
\hline 4 & 208 & 0.36 & \\
\hline 5 & 252 & 0.42 & \\
\hline
\end{tabular}

Table 6.4 Cutting Load Required to De-frost Dry Coconuts

It is evident from the table that the load required to remove the dried coconut shell is greater than the load required for removing the mature coconut shell. Furthermore, the graphs are represented for dried and ripe coconuts so that the coconut $\mathrm{X}$ dimension is taken as an independent parameter on the $\mathrm{X}$ axis and the cutting load is taken along the $\mathrm{Y}$ axis. This is due to the cutting load varies according to the size of the coconut. The graphic is shown below. 


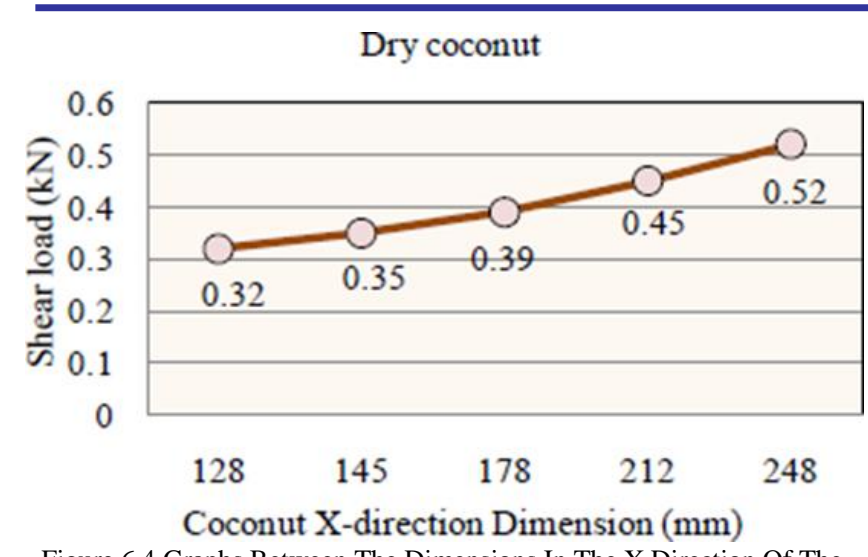

Figure 6.4 Graphs Between The Dimensions In The X Direction Of The Dry Coconut And The Cutting Load To Remove The Coconut.

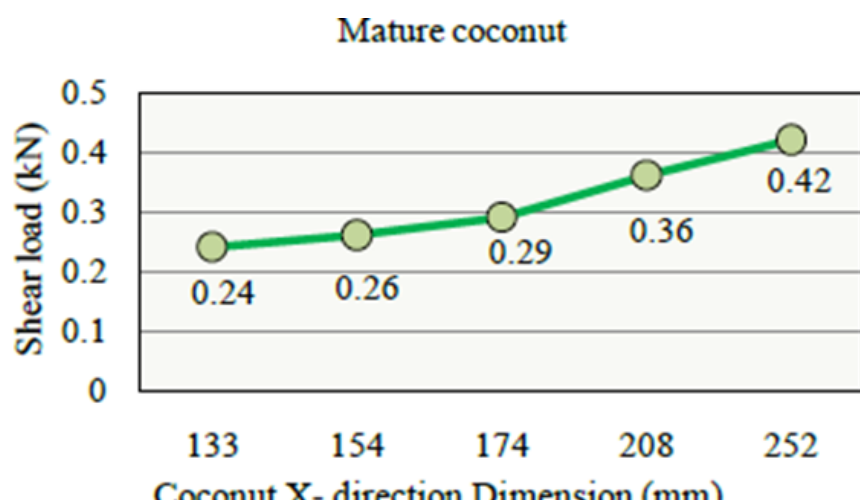

Figure 6.5 Graphs Between The Dimensions Of The X Direction Of The Ripe Coconut And The Cutting Load To Remove The Coconut Shell.

From the graphs it can be deduced that the cutting load varies linearly with respect to the size of the coconut.

\section{VII.ERGONOMIC CONSIDERATIONS}

This is the part of ergonomics that manages and measures the extent of the outer human body in static and dynamic conditions. Anthropometry focuses, as appeared in Figure 6.1, have been considered for the coconut fiber extraction machine that chooses its size (Figure 6.2)

\subsection{QUALITY FUNCTION DEPLOYMENT (QFD)}

The usage of the quality capacity (QFD) is a "technique to change client needs on the nature of configuration, to envision the capacities that structure quality and to execute quality plan strategies in subsystems and segments and, at last, precedent, in explicit components of the generation procedure ".
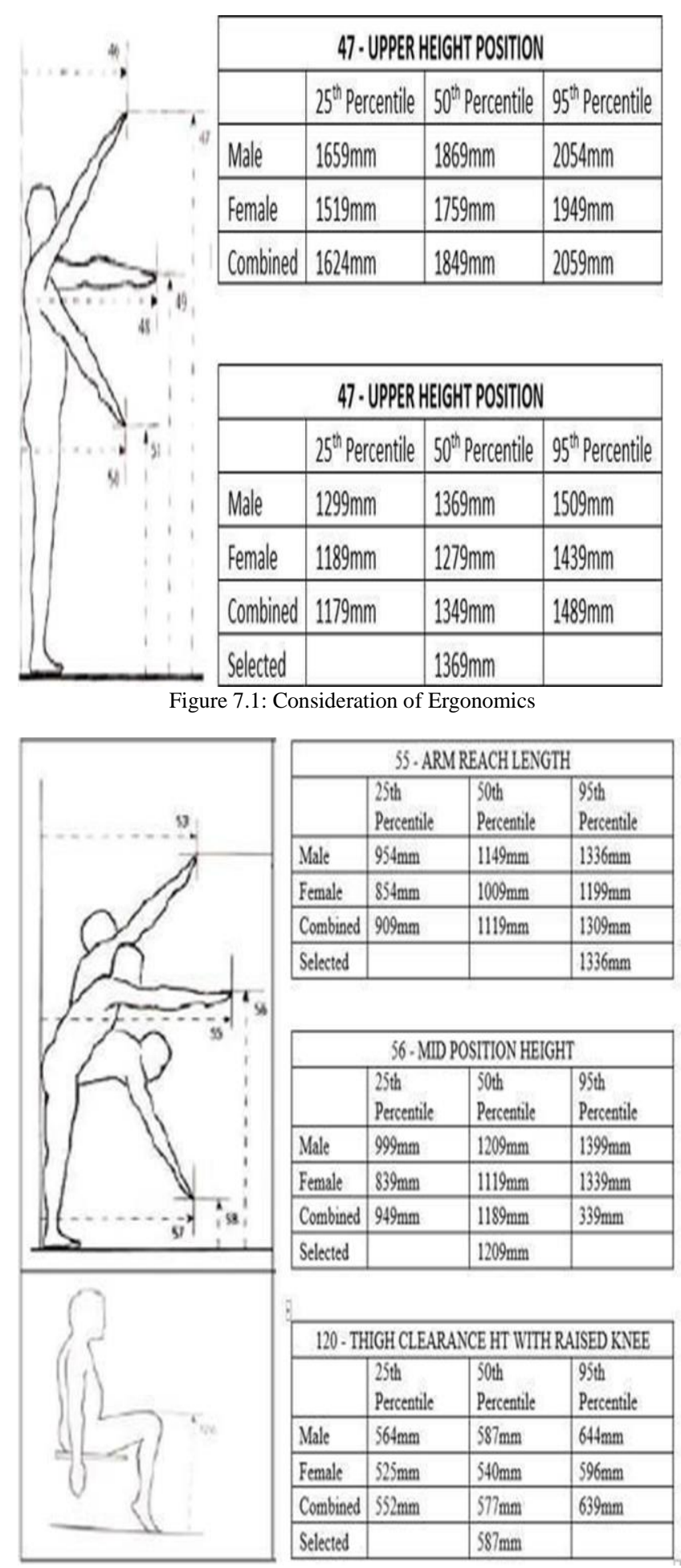

Figure 7.2: Consideration of Ergonomics

\subsection{QFD RESULTS}

1. The QFDs are achieved from the experience of farmers and coir industries, as shown in Table

2. The results of the QFD house are simple, functional and ergonomics is one of the main priorities.

- $\quad$ The machine must be compact.

- Functionality.

- $\quad$ Safety against failure.

- User friendly to assemble.

- Less maintenance. 
- Less cost.

- Good ergonomics.

\section{VIII.FABRICATED MODEL}

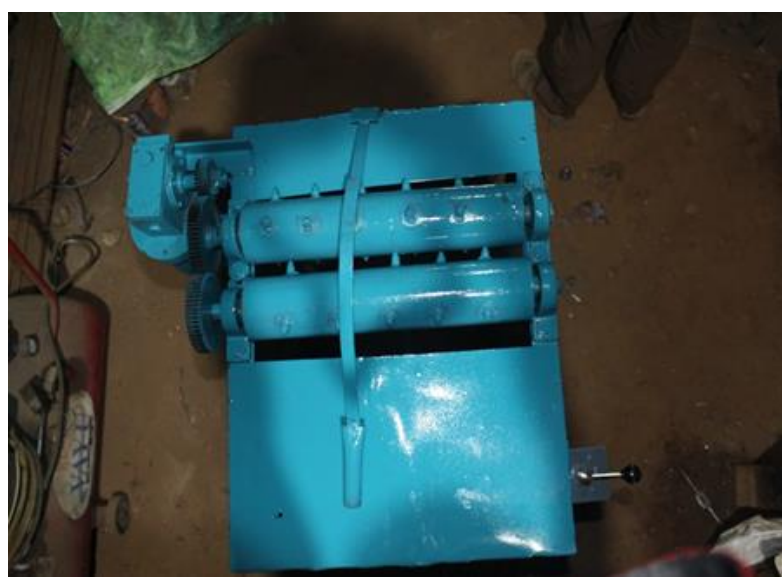

Figure 8.1: Top View

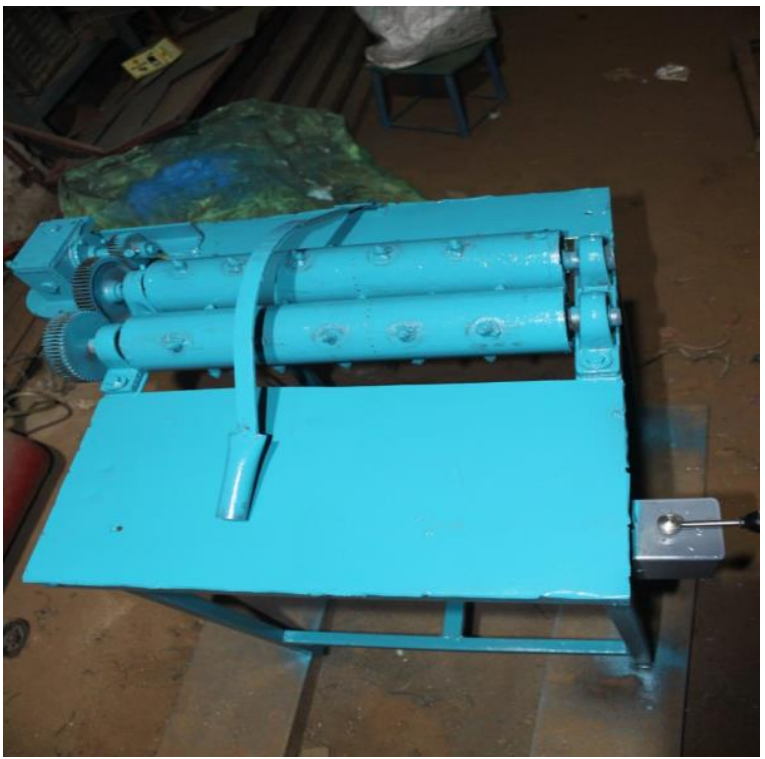

Figure 8.2: Angled View

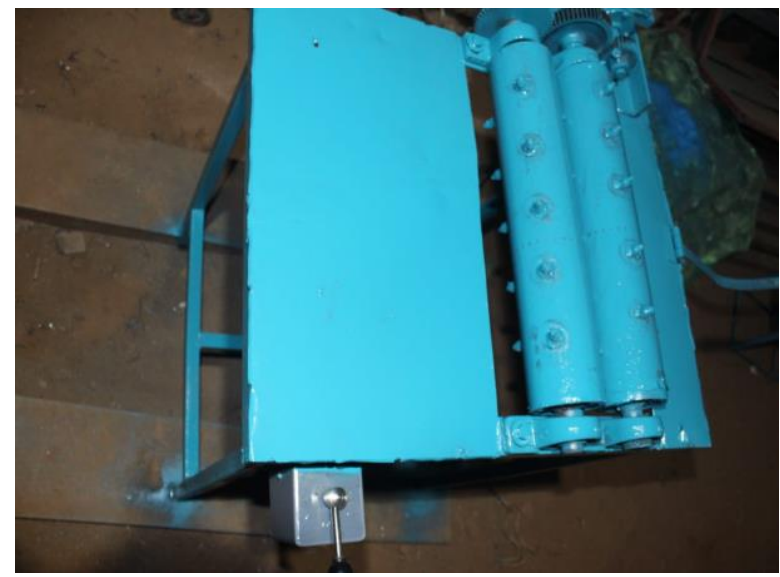

Figure 8.3: Side view

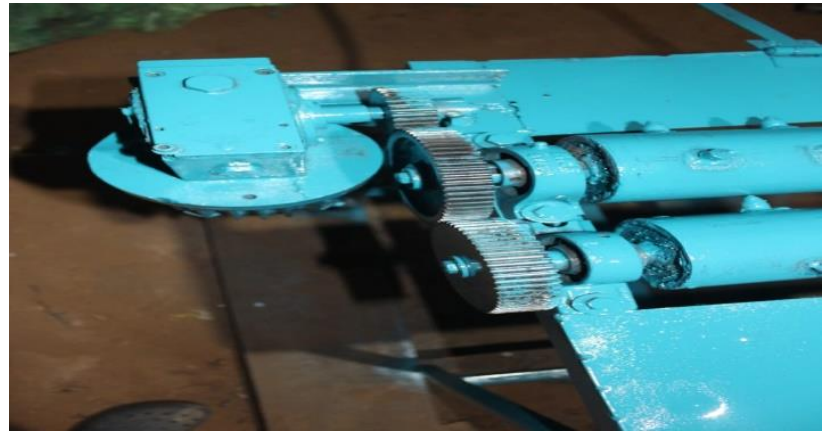

Figure 8.4: Zoomed view

\section{IX.CONCLUSION}

Coconut is grown on a large scale in India; this horticultural crop has become a source of income and employment in many parts of the southern states. All coconut parts earn an income and some are even exported as coconut fibre products. The post-harvest operation of the coconut is a tedious job to do and involves a lot of heavy human work. The skilled workers for coconut peeling are decreasing these days. Many attempts have been made to mechanize this operation by developing various tools and even electrical machinery.

The intention of this work is to provide a semiautomatic coconut bark driven by an engine with the elimination of the disadvantages of previously developed tools and machinery. The proposed machine uses rotating cylinders with cutting teeth joined together on its surface, which rolls in the opposite direction to eliminate the shell of the coconut shell. An arrangement to adjust the distance between the rotating cylinders is made to adapt to various sizes of coconuts due to the change in variety and maturity. The cutting screws are attached to the cylinders with fixing devices so that it is possible to easily replace damaged tires. Consequently, the proposed machine will be carefully designed, produced and tested. A machine has been developed for barking the coconut that husks the coconuts without breaking the nuts and distorting the extracted shells. The machine is user friendly and works effectively and an average of 180-200 nuts per hour. The introduction of this machine diminishes the problem fibre extraction from coconut fibre associated with the use of some mechanized equipment, as well as heavy work

Risks related to the use of machetes and spikes to bark coconut. It also eliminates dependence on the supply of public epileptic electricity in rural areas. The machine capable to produce around of 200 nuts per hour. Implementing this machine to cultivated areas can reduce the labour required to peel coconuts. .

The following are some conclusions based on the new derivative process and the new product designed and its functions.

- $\quad$ Based on the ideas of structure and advancement, item generation. This item can decalcify 200 coconuts for every hour and will be valuable for ranchers and little scale coconut fibre businesses.

- $\quad$ Easy to assemble.

- Low maintenance. 
- On the market, this model is conservative with a decent scope of profitability requiring little to no effort and wellbeing.

\section{X.REFERENCES}

[1] Y. Prashant, C. Gopinath and VigneshRavichandran, "Design and development of machines for the extraction of coconut fibers", SASTech Journal Volume 13, number 1, April 2014.

[2] BN Nwankwojike, O. Onuba and U. Ogbonna, "Development of a coconut grinder machine for small-scale rural farmers" International journal of innovative technology and creative engineering (Edition: 2045-8711) Vol.2 No. 3 March 2012.

[3] 3. Nijaguna "Coconut Dehusker" Journal on Food Engineering (1986) 287-301.

[4] AbiVargheser and Jippu Jacob, "A Review of Coconut Shell Machines", International Journal of Design and Manufacturing

Technology, Volume 5, Number 3, September- December (2014).

[5] Edward D. Hill, "Coconut Shell Removal Tool", U.S. Pat. No. 4,383,479, May 17, 1983

[6] René Marot, "Apparatus for removing fibers from coconuts or similar" United States Patent 983.631 dated 3 February 1911.

[7] Coconut Machines, www.coconutmachine.com/index.php?mid=72, obtained on 15 January 2014.

[8] Debkumar Chakrabarthi, India Anthropometric dimensions, NID, Ahmedabad: National Institute of Design, pp100, 1997.

[9] Coir machines, coconut fiber extraction machines, http://www.coirmachines.net/coir-fibre- extraction-machinery.html, obtained on 15 January 2014. 